\title{
NATURAL ABUNDANCE OF STABLE ISOTOPES REVEALS THE DIVERSITY OF
}

\section{CARNIVOROUS PLANT DIETS}

Francis Q. BREARLEY $\bullet S$ Chool of Science and the Environment $\bullet M$ anchester $M$ etropolitan University -Chester Street • M anchester •M 1 5GD・UK・f.q.brearley@mmu.ac.uk

Keywords: carbon, Cephalotus, Dionaea, D rosera, Nepenthes, nitrogen, nutrients, Roridula, stable isotopes.

Ever since carnivorous plants were first described and studied by early naturalists (e.g., Darwin 1875), there has been continued interest in the relationship between the uptake of nutrients from invertebrate prey and the growth and performance of these plants. Although it is now thought that multiple nutrients appear to limit the growth of most carnivorous plants (Ellison 2006), of particular interest has been nitrogen $(\mathrm{N})$, as many studies have shown that carnivorous plants can obtain extra $\mathrm{N}$ from the digestion of their prey.

In recent years, the use of stable isotopes has increased in ecological research, especially to shed further light on carbon $(\mathrm{C})$ and $\mathrm{N}$ cycling in ecosystems. Stable isotopes are elements which have an extra neutron e.g., ${ }^{15} \mathrm{~N}$ versus the more common ${ }^{14} \mathrm{~N}$. They are relatively uncommon in the environment where typically less than $1 / 2 \%$ of $\mathrm{N}$ atoms are the heavier ${ }^{15} \mathrm{~N}$ isotope, but they are often sufficiently abundant to use as non-radioactive tracers of el emental movement through ecosystems. Stable isotopes are measured using an isotope ratio mass spectrometer and recorded using delta $(\delta)$ notation. In the case of $\mathrm{N}$, this is the ratio of ${ }^{15} \mathrm{~N}:{ }^{14} \mathrm{~N}$ relative to that of atmospheric $\mathrm{N}$ (which has $0.36765 \%{ }^{15} \mathrm{~N}$ ): positive $\delta$ values (measured on a \%o scale) mean more ${ }^{15} \mathrm{~N}$ than the atmospheric standard, whereas negative values mean less ${ }^{15} \mathrm{~N}$ than this reference value. Given the importance of $\mathrm{N}$ in the growth of many plants, and especially carnivorous plants, the use of $\mathrm{N}$ isotopes has proved very useful in shedding further light on $\mathrm{N}$ nutrition in these organisms. They are particularly useful when the question of interest is not necessarily "how much?" but "where from?"

As trophic levels are ascended, there is an increase in the $\delta^{15} \mathrm{~N}$ values of the organisms by about $3.4 \%$ relative to their food substrate (Post 2002) and, therefore, insects generally have a more enriched $\delta^{15} \mathrm{~N}$ signature than the majority of plant foliage upon which they feed. By using simple mathematical mixing models (e.g., M oran et al. 2001, 2003; B rearley et al. 2003) which compare the $\delta^{15} \mathrm{~N}$ values of reference plants which are not capturing insects with those which have consumed and digested insects, it is possible to calculate the uptake of $\mathrm{N}$ from insects, provided the $\delta^{15} \mathrm{~N}$ values of the insect prey are known.

The first study to use stable isotope methodology to examine $\mathrm{N}$ uptake from insects was that of Schulze et al. (1991), who looked at various A ustralian D rosera species. They found that N derived from insect prey was much greater in larger shrub-like or vine-forming individuals than in smaller rosette-forming plants. Follow-on work assessing the proportion of $\mathrm{N}$ obtained from insect prey in a wider range of species (Schulze et al. 1997) suggested that all of the $N$ in young leaves of Nepenthes mi rabil is was obtained from insects but this val ue declined as pitchers aged and $\mathrm{N}$ was re-allocated. In Cephalotus follicularis, it was suggested that only plants with more than four open, and presumably functional, pitchers obtained a measurable amount of $\mathrm{N}$ from insect capture (Schulze et al. 1997). $M$ ore recent work by Millett et al. (2003), using a similar methodology, suggested that the mean proportion of $\mathrm{N}$ derived from insects was $50 \%$ in three $\mathrm{B}$ ritish populations of D rosera rotundifolia.

In these initial studies there were a number of caveats: researchers often used non-carnivorous plants as reference plants to compare with the carnivorous plants but other factors may affect the 
reference plants' $\delta^{15} \mathrm{~N}$ signature such as symbiotic root-inhabiting mycorrhizal fungal associations, rooting depth and the dominant form of $\mathrm{N}$ (i.e., ammonium, nitrate, or even organic $\mathrm{N}$ ) taken up by the plants (Högberg 1997; Robinson 2001). In addition, there may be internal physiological processes at work which will affect plant $\delta^{15} \mathrm{~N}$ such as re-absorption of nutrients. Therefore it is more appropriate for researchers to use reference plants as closely related as possible to the carnivorous plants under study.

To determine $\mathrm{N}$ uptake in Dionaea muscipula, Schulze et al. (2001) employed a more complex strategy due to the wide range in $\delta^{15} \mathrm{~N}$ values of different insect prey species. Total $\mathrm{N}$ derived from insects was determined as a function of the dependence of each plant part (e.g., roots, leaves, flowers) on $\mathrm{N}$ obtained from the traps of each plant and the proportional weight of each plant part to the plant's total weight. Schulze et al. (2001) showed that the proportion of insect derived N decreased from an early successional state after fire (c. $75 \%$ ) to lower values (c. $45 \%$ ) as other grasses and shrubs overtopped the fly traps.

$M$ any Nepenthes species catch a high diversity of prey, with ants being their most common prey item (M oran 1996; Di Giusto et al. 2008). However, N. albomarginata has a strong preference for catching termites (M erbach et al. 2002). M oran et al. (2001) compared the $\mathrm{N}$ isotope ratios of the termite-catching $\mathrm{N}$. albomarginata with that of $\mathrm{N}$. rafflesiana which prefers ants. There were considerable differences in the two species' $\mathrm{N}$ isotope ratios (N. albomarginata: $-2.1 \%$; N. rafflesiana: $1.9 \%$ ) which could be related to the clear differences in $\delta^{15} \mathrm{~N}$ of the two prey insect groups (termites: $-4.0 \%$; ants: $2.0 \%$ ). In a more interesting twist on carnivorous diets, we often think that carnivorous plants obtain their nutrients from insect prey (and occasionally other fauna) but there is actually little stopping them obtaining nutrients from leaves if they happen to fall into the pitchers, although many species have a lid which may prevent this from happening. N. ampullaria has an unusual habit and morphology as it forms clusters of pitchers on the closed canopy forest floor and the pitcher mouth is not covered by the lid as in most $N$ epenthes species. These observations led M oran et al. (2003) to suggest that that it may be more involved in obtaining nutrients from leaf litter than other species. This was tested by examining the stable isotope ratios of plants growing in the open $\left(-0.20 \%\right.$ ) compared with those under a forest canopy $\left(-2.22 \%\right.$ ). A s the $\delta^{15} \mathrm{~N}$ of leaf litter was much more negative than that of the insect prey, they concluded that plants under the canopy were obtaining a sizable proportion of their $\mathrm{N}$ from leaf litter. The most recent addition to the diversity of food items trapped by pitcher plants is that of animal faeces which are used by N. lowii in tropical montane forests where ant numbers are much lower. Clarke et al. (2009) showed that faeces of tree shrews, which feed on exudates from the pitcher lid whilst squatting over the pitcher opening, accounted for almost the entire $\mathrm{N}$ utilised by this species in some cases.

A nother species in which $\mathrm{N}$ uptake has been studied using stable isotopes is the sticky-leaved Roridula gorgonias over which inclusion into the carnivorous plant pantheon has been questioned as the plants do not produce any digestive enzymes. However, they do have notably elevated $\delta^{15} \mathrm{~N}$ values (M idgley \& Stock 1998) indicating that a considerable proportion of plant $\mathrm{N}$ is derived from an insect source. When insects become trapped on the hairs of Roridula they are rapidly consumed by hemipterans resident on the plant which excrete the undigested insect remains; the $\mathrm{N}$ within which appears to be absorbed by the leaf surfaces of Roridula (Ellis \& M idgley 1996). Furthermore, another species of Roridula hosts spiders which prey on the hemipterans and it was shown that plants with a higher density of spiders had a lower hemipteran density resulting in less $\mathrm{N}$ obtained from insect excretions (A nderson $\&$ M idgley 2002). It would be interesting to determine the relative importance of hemipteran versus spider excretions in the $\mathrm{N}$ nutrition of the two Roridula species although this would probably require an isotopic labeling study. Overall, Roridula receives up to $70 \%$ of its $\mathrm{N}$ from insects 
although only when the hemipterans are present at a high density (A nderson \& M idgley 2002) showing a fascinating three-way mutual istic interaction in the feeding strategy of this carnivorous plant.

Finally, stable isotopes have also been used in studies of pollution ecology (e.g., Van Dover et al. 1992), specifically to trace their sources. A potentially useful example, where the source of $\mathrm{N}$ for D rosera species has been examined in relation to changing $\mathrm{N}$ inputs, is that of A kagi and Osawa (2005), who showed that $\delta^{15} \mathrm{~N}$ of D. rotundifolia in a J apanese bog was increased where there were more recreational benches; they suggested that this was due to increased human "pollution". However, there is an alternative explanation for this relationship as plants with higher $\delta^{15} \mathrm{~N}$ values had a larger number of trapped insects. This relationship was weak but is a confounding factor in the results which indicates that this method may have potential if utilised appropriately.

In conclusion, $\mathrm{N}$ isotopes have been show $\mathrm{n}$ to be a powerful tool to examine $\mathrm{N}$ uptake in carnivorous plants as insect $\delta^{15} \mathrm{~N}$ values are generally enriched in relation to plant $\delta^{15} \mathrm{~N}$ values thus allowing us to trace movement of $\mathrm{N}$ in the ecosystem. When the question of interest is "how much?", it has been shown that most carnivorous plants obtain up to $75 \%$ of their $N$ from insect prey. When the question of interest is "where from?" using N epenthes as a specific example, recent use of stable isotopes has revealed that certain species have a much more specialised diet than originally envisaged.

A cknowledgements: I thank J onathan M oran and Gemma M uckle for helpful comments on the manuscript.

\section{References}

A nderson, B., and Midgley, J.J. 2002. It takes two to tango but three is a tangle: mutualisms and cheaters on the carnivorous plant Roridula. Oecologia 132: 369-373.

A kagi, T., and O sawa, K . 2005. Possible input of nitrogen of visitors' origin on a protected peatland. Environmental M anagement 35: 461-467.

B rearley, F.Q., Press, M .C., and Scholes, J.D. 2003. N utrients obtained from leaf litter can improve the growth of dipterocarp seedlings. New Phytologist 160: 101-110.

Clarke, C.M ., Bauer, U., L ee, C.C., Tuen, A .A ., Rembold, K ., and M oran, J.A . 2009. Tree shrew lavatories: a novel nitrogen sequestration strategy in a tropical pitcher plant. B iology Letters 5: 632-635.

Darwin, C. 1875. Insectivorous Plants. John M urray, London, UK.

Di Giusto, B., Grosbois, V., Fargeas, E., M arshall, D.J ., and Gaume, L . 2008. Contribution of pitcher fragrance and fluid viscosity to high prey diversity in a Nepenthes carnivorous plant from Borneo. Journal of Biosciences 33: 121-136.

Ellis, A.G., and Midgley, J.J. 1996. A new plant-animal mutualism involving a plant with sticky leaves and a resident hemipteran insect. Oecologia 106: 478-481.

Ellison, A.M . 2006. Nutrient limitation and stoichiometry of carnivorous plants. Plant Biology 8: 740-747.

Högberg, P. 1997. ${ }^{15} \mathrm{~N}$ natural abundance in soil-plant systems. New Phytologist 137: 179-203 \& 139: 595.

M erbach, M .A., M erbach, D.J ., M aschwitz, U., B ooth, W.E., Fiala, B., and Zizka, G. 2002. M ass march of termites into the deadly trap. Nature 415: 36-37.

M idgley, J.J., and Stock, W.D. 1998. Natural abundance of $\delta^{15} \mathrm{~N}$ confirms insectivorous habit of Roridula gorgonias, despite it having no proteolytic enzymes. A nnals of B otany 82: 387-388.

M illett J., Jones R.I., and Waldron, S. 2003. The contribution of insect prey to the total nitrogen content of sundews (D rosera spp.) determined in situ by stable isotope analysis. New Phytologist 158: 527-534. 
M oran, J.A. 1996. Pitcher dimorphism, prey composition and the mechanisms of prey attraction in the pitcher plant Nepenthes rafflesiana in B orneo. J ournal of Ecology 84: 515-525.

M oran, J.A., M erbach, M .A., Livingston, N.J., Clarke, C.M ., and B ooth, W.E. 2001. Termite prey specialization in the pitcher plant $N$ epenthes al bomarginata- evidence from stable isotope analysis. A nnals of B otany 88: 307-311.

M oran J.A., Clarke C.M ., and Hawkins B.J. 2003. From carnivore to detritivore? I sotopic evidence for leaf litter utilization by the tropical pitcher plant N epenthes ampullaria. International J ournal of Plant Sciences. 164: 635-639.

Post, D.M . 2002. Using stable isotopes to estimate trophic position: models, methods, and assumptions. Ecology 83: 703-718.

Robinson, D. 2001. $8^{5} \mathrm{~N}$ as an integrator of the nitrogen cycle. Trends in Ecology and Evolution 16: 153-162.

Schulze, E.-D., Gebauer, G., Schulze, W., and Pate, J.S. 1991. The utilization of nitrogen from insect capture by different growth forms of D rosera from southwest A ustralia. O ecologia 87: 240-246. Schulze, W., Schulze, E.-D., Pate, J.S., and Gillison, A.N. 1997. The nitrogen supply from soils and insects during growth of the pitcher plants Nepenthes mirabilis, Cephalotus follicularis and Darlingtonia californica. Oecologia 112: 464-471.

Schulze, W., Schulze, E.-D., Schulze, I., and Oren, R. 2001. Quantification of insect nitrogen utilization by the Venus fly trap Dionaea muscipula catching prey with highly variable isotope signatures. J ournal of Experimental B otany 52: 1041-1049.

Van D over, C.L., Grassie, J.F., Fry, B., Garritt, R.H., and Starczak, V.R. 1992. Stable isotope evidence for entry of sewage-derived organic material into a deep-sea food web. N ature 360: 153-156.

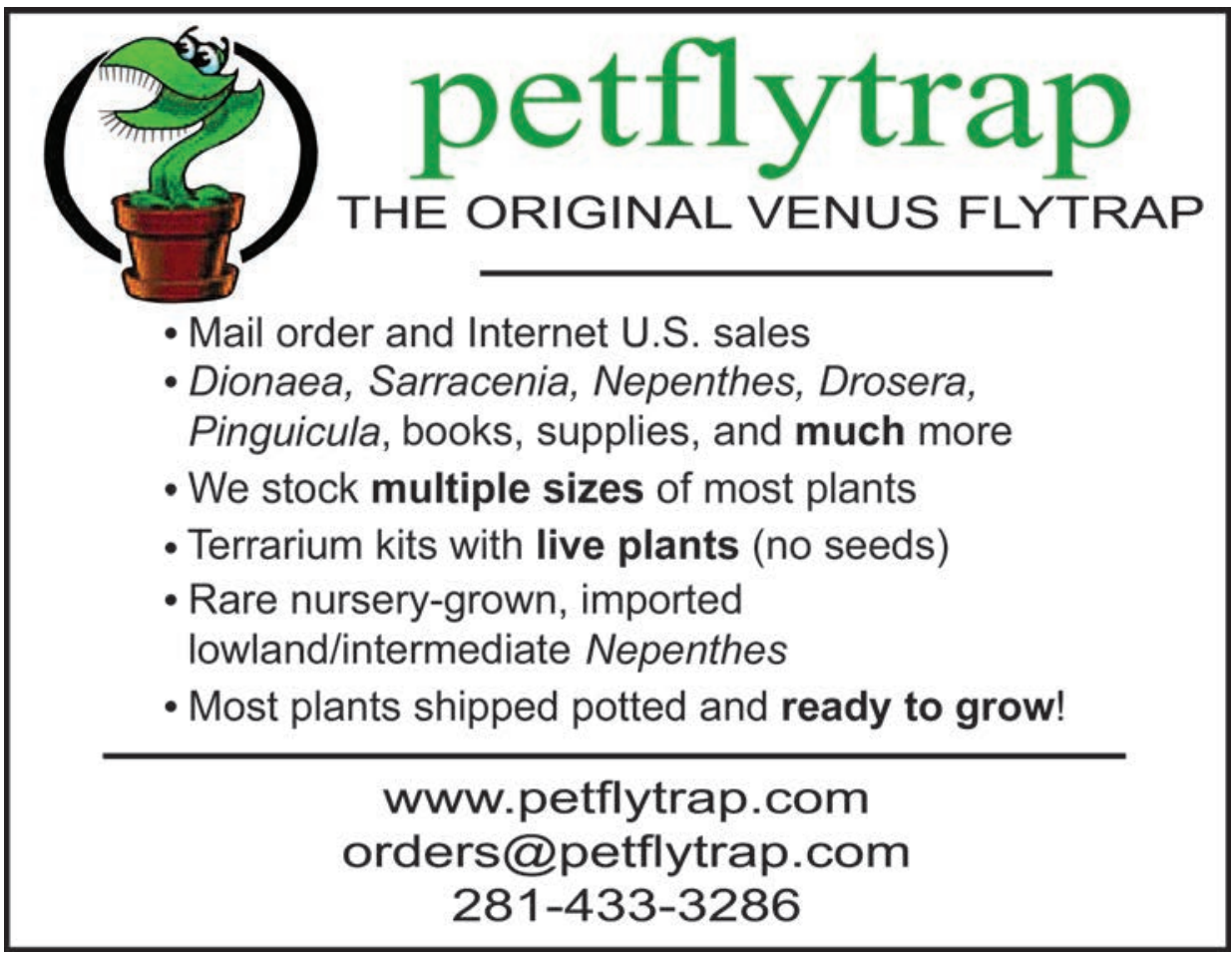

